\title{
YY1 overexpression is associated with poor prognosis and metastasis-free survival in patients suffering osteosarcoma
}

\author{
Filomena de Nigris ${ }^{1,6^{*}+}$, Licciana Zanella ${ }^{2+}$, Francesco Cacciatore ${ }^{3+}$, Anna De Chiara ${ }^{4}$, Flavio Fazioli ${ }^{5}$, \\ Gennaro Chiappetta ${ }^{4}$, Gaetano Apice ${ }^{5}$, Teresa Infante ${ }^{6}$, Mario Monaco ${ }^{4}$, Raffaele Rossiello ${ }^{8}$, Gaetano De Rosa ${ }^{7}$, \\ Marco Alberghini ${ }^{2}$ and Claudio Napoli, ${ }^{1,6}$
}

\begin{abstract}
Background: The polycomb transcription factor Yin Yang 1 (YY1) overexpression can be causally implicated in experimental tumor growth and metastasization. To date, there is no clinical evidence of YY1 involvement in outcome of patients with osteosarcoma. Prognosis of osteosarcoma is still severe and only few patients survive beyond five years. We performed a prospective immunohistochemistry analysis to correlate YY1 immunostaining with metastatic development and survival in a selected homogeneous group of patients with osteosarcoma.

Methods: We studied 41 patients suffering from osteosarcoma (stage II-IVa). Multivariate analysis was performed using Cox proportional hazard regression to evaluate the correlation between YY1 expression and both metastasis development and mortality.

Results: YY1 protein is not usually present in normal bone; in contrast, a high number of patients (61\%) showed a high score of YY1 positive cells (51-100\%) and 39\% had a low score (10-50\% positive cells). No statistical difference was found in histology, anatomic sites, or response to chemotherapy between the two degrees of YY1 expression. Cox regression analysis demonstrated that the highest score of YY1 expression was predictive of both low metastasis-free survival $(\mathrm{HR}=4.690,95 \% \mathrm{Cl}=1.079-20.396 ; \mathrm{p}=0.039)$ and poor overall survival $(\mathrm{HR}=8.353,95 \% \mathrm{Cl}$ $=1.863-37.451 \mathrm{p}=0.006)$ regardless of the effects of covariates such as age, gender, histology and chemonecrosis.

Conclusion: Overexpression of YY1 in primary site of osteosarcoma is associated with the occurrence of metastasis and poor clinical outcome.
\end{abstract}

\section{Background}

Osteosarcoma is the most common primary malignant bone tumor in adolescents and children [1]. It occurs frequently in long bones and metastasizes preferentially to the lung [1]. Despite recent advances in chemotherapy, the 5-year event-free survival and overall survival rates, closely linked to grade of osteosarcoma, are around $50-60 \%$. This is due to the development of resistance to multiple types of chemotherapy and radiotherapy [2-4]. Clinical stage of the disease and several clinical biomarkers have been correlated with the

\footnotetext{
*Correspondence: filomena.denigris@unina2.it

+ Contributed equally

'Department of General Pathology, Division of Clinical Pathology and U.O.C. Immunohematology, Second University of Naples, 80138 Naples, Italy Full list of author information is available at the end of the article
}

outcome [5-11]. Nonetheless, these prognostic factors have limited utility in terms of predicting survival [12].

The ubiquitous, conserved, multifunctional polycomb transcription factor Yin Yang 1 (YY1) plays a pivotal role in biological processes [13-15]. YY1 regulates embryonic blood formation and its downstream hox genes, $\mathrm{X}$ chromosome inactivation, differentiation, and cell cycle $[13,14]$. The majority of the data are consistent with the hypothesis that YY1 overexpression and/or its activation is associated with unchecked cellular proliferation, resistance to apoptotic stimuli, tumorigenesis and metastatic potential. We studied the role of YY1 in osteosarcoma carcinogenesis and tumor progression. YY1 is overexpressed in osteosarcoma cells and bioptic specimens, and is correlated with a high degree of

\section{Biomed Central}


malignancy $[16,17]$. Moreover, YY1 silencing has been shown to be sufficient to significantly reduce osteosarcoma metastatic growth and neoangiogenesis in a nude mice model [18-20]. To date, there is no evidence of correlation between YY1 overexpression and clinical outcome in osteosarcoma patients. Thus, we designed a prospective study to analyze whether YY1 expression in the primary tumor of osteosarcoma patients could predict metastasis-free and overall survival.

\section{Methods \\ Patients}

We enrolled 41 osteosarcoma patients (stage II-IVa UICC/AJCC classification) from the Department of Pathology of the Istituto Ortopedico Rizzoli (Bologna, Italy) and from the Division of Surgical Pathology, Istituto Nationale Tumori, Fondazione G. Pascale (Naples, Italy), under their Local Ethical Committee approval. We used the bioptic samples of primary tumor before any treatment (see below). Of the 41 patients, 14 had metastasis at the first visit (synchronous), 15 developed metastasis during follow-up (metachronous) and 12 were metastasis-free. Metastases were localized in lung and the primary sites were in extremity bones. Extraskeletal, periosteal, and paraosteal osteosarcomas were excluded from this study. All slides of the cases were reviewed by two pathologists to confirm diagnosis. Patients received preoperative, postoperative or no chemotherapy according to degree of tumor stage. Necrosis area was defined by using the Huvos grading system, as described in detail $[21,22]$. Accordingly, we subdivided patients into two groups $(<90 \%)$ and $(\geq 90 \%)$ based on chemonecrosis area as indicated by the European Cooperative Osteosarcoma Study Group coordinated by the Istituto Ortopedico Rizzoli (COSS) [21,22], a partner of the present study.

Chemotherapy protocols included methotrexate $(12 \mathrm{~g} /$ $\left.\mathrm{m}^{2}\right)$ with leucovorin rescue, cisplatin $\left(90-150 \mathrm{mg} / \mathrm{m}^{2}\right)$, doxorubicin $\left(60-90 \mathrm{mg} / \mathrm{m}^{2}\right)$, and ifosfamide $\left(6-10 \mathrm{~g} / \mathrm{m}^{2}\right)$. The scheduled duration of chemotherapy ranged from 24 to 38 weeks. For chemotherapy patients, surgery was scheduled to take place between weeks 9 and 11 and radiotherapy was not used. We collected clinical data from all patients including age, sex, tumor site, necrosis area after chemotherapy and surgical stage.

\section{Immunohistochemistry}

Biopsies before chemotherapy were fixed and paraffin embedded. Conventional immunohistochemical studies were performed on 5-6 $\mu \mathrm{m}$ section, as previously described in detail [16,22]. Briefly, slides were immersed in a water bath (W-cap Bioptica) and incubated for 30 minutes at $95^{\circ} \mathrm{C}$, then cooled for 20 minutes at room temperature. Sections were then incubated for $10 \mathrm{~min}$ utes in $3 \%$ hydrogen peroxide in distilled water, and washed in PBS for 5 minutes. Slides were incubated with the primary antibody (mouse-monoclonal YY1 diluted 1:100 sc7341 Santa Cruz) for 30 minutes in a Dako Autostainer device. The signal was then visualized with streptavidina-biotina Dako REAL Detection System Peroxidase/DAB, Rabbit/Mouse Dako Autostainer. Slides were counterstained with hematoxylin. Washing steps were included after each incubation. All samples were stained with vimentin as tissue quality controls while positive and negative conventional controls were used to test antibody as already reported [16]. All controls gave satisfactory and reproducible results. Digital photos were obtained with Olympus Vanox AHBS3. The staining of tumor cells for evaluation of YY1 was scored from 0 to 4 ( $0=$ no staining; $1=$ weak $1-25 \%$ positive cells; $2=$ moderate $26 \%-50 \%$ positive cells; $3=$ strong $51 \%-75 \%$ positive cells; $4=$ very strong $76 \%-100 \%$ positive cells. This score was checked by two independent observers blinded for clinical outcome or other biological tumor features. Discrepant cases were decided on consensus.

\section{Statistical analysis}

Data were analyzed with SPSS 13.0 software. Results are reported as mean \pm SD. YY1 was considered as a discrete variable and the patients were stratified into two classes: high score as $3-4,(>51-100 \%$ positive cells $)$ and low score as $0-2,(0-<50 \%$ positive cells $)$ of YY1. ANOVA was used to assess difference for continuous variables (age and mean follow-up) while Pearson chi square test was used to examine differences between YY1 expression and each clinical variable: gender, tumor site, histotype, chemonecrosis, presence of metastasis at diagnosis and occurrence of metastasis at follow-up ( $\mathrm{n}=$ 41). Survival periods were counted in months from the date of first visit to date of death or last follow-up before study closure. Follow-up data started at time of diagnosis allowing a minimum of 3.8 months (mean $47.0 \pm 25.3$ month range, 3.8-95 months). Mean age of the sample was $19.4 \pm 15.5$ with a range from 4 to 76 years. Metastasis-free period was counted in months from the date of surgery to date of detection of first metastasis, since no local relapses occurred. We used life-table method to estimate the metastasis-free survival and overall survival for low and high levels of YY1 expression. Multivariate Cox regression analysis was used to evaluate the effect of YY1 expression on metastasis occurrence and survival independently of age, gender, histotype and chemonecrosis. A p value $<0.05$ was considered as statistically significant.

\section{Results}

YY1 overexpression in osteosarcoma tissues

Immunohistochemistry revealed that all normal bone tissues analyzed $(n=10)$ were almost negative to YY1 


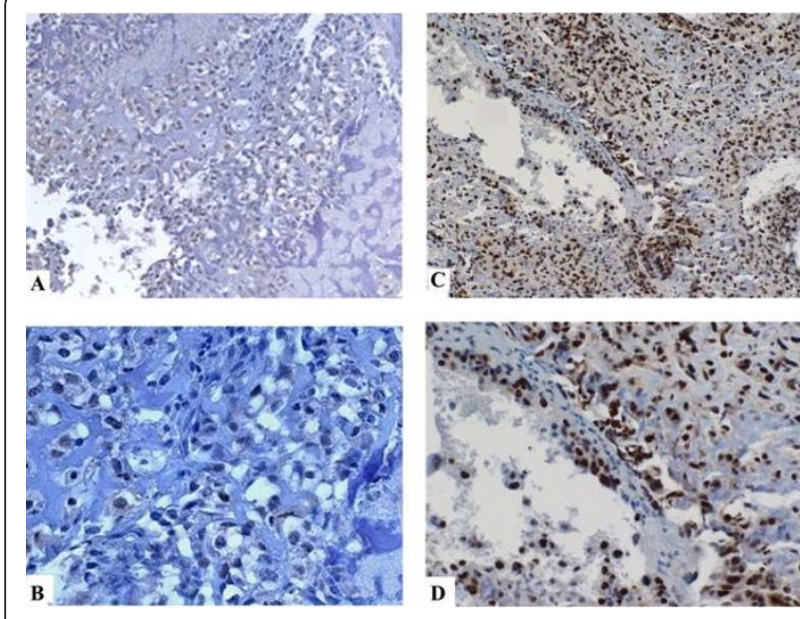

Figure 1 Two comparative examples of $\mathrm{YY} 1$ expression in osteosarcomas. A, osteobastic osteosarcoma specimen with 2 as score of immunoreactivity to $Y Y 1$ at lower magnification (20x); $\mathbf{B}$, the same specimen as in A at higher magnification (100x); C, osteoblastic osteosarcoma specimen with 4 as score of immunoreactivity to YY1 (20x); D, the same osteoblastic osteosarcoma specimen as in $\mathbf{C}$ at higher magnification (100x). YY1 protein was localized in nuclei of the cells.

antibody or in some cases normal bone showed faint and diffuse cytoplasm staining, as previously reported [16]. Figure 1 shows two representative examples of osteosarcoma with the low score (2) and high score (4) of YY1 antibody localized predominantly in nuclei (95\%). Table 1 shows YY1 scoring with respect to clinical variables. Table 2 summarizes the characteristics of the study population stratified by high and low YY1 expression (see methods). A total of $61 \%$ of tumor samples were positive to YY1 staining (nuclear staining) with strong intensity (score $3-4,>51-100 \%$ positive cells) while $39 \%$ showed a lower degree of YY1 staining (score $1-2,<50 \%$ of positive cells). Distal femur and tibia were the most common sites ( $53.7 \%$ and $19.5 \%$ respectively). The majority of tumors arose on extremities. There was no difference in degree of YY1 expression in histological subgroups (i.e. chondroblastic, fibroblastic and osteoblastic types, $\mathrm{p}=0.557$ ) and age. Twenty-seven patients were free of metastasis at baseline while 15 (55.6\%) developed metastasis during follow-up. Of these, $80 \%$ were positive to YY1 (51-100\% positive cells) ( $\mathrm{p}=$ 0.004 ). In univariate analysis, death occurred in $64 \%$ of YY1 strong positive patients $(\mathrm{p}=0.005)$. Importantly, multivariate Cox regression analysis revealed that a high level of YY1 expression (score 3-4) was predictive of poor metastasis-free survival $(\mathrm{HR}=4.690,95 \% \mathrm{CI}=$ 1.079-20.396; $\mathrm{p}=0.039$ ) (Table 3 and Figure 2). The estimated overall survival (after 60 months of follow-up) calculated by life-table method (Table 4) was 34\% for patients with a high YY1 score and $79 \%$ for those with a low YY1 score. Multivariate Cox regression analysis indicated that YY1 expression is predictive of mortality $(\mathrm{HR}=8.353,95 \% \mathrm{CI}=1.863-37.451, \mathrm{p}=0.006)$ as an independent variable with respect to age, gender, histotype and chemonecrosis (Figure 3 and Table 5).

\section{Discussion}

The present study demonstrates that a high level of YY1 protein expression increases the risk of metastasis (4.69fold) and poor survival (8.35-fold) in osteosarcoma patients independently of covariates such as age, gender, histotype, and chemonecrosis. We report that the highest range of YY1 expression is a statistically significant prognostic factor setting the 5-year survival rate to $34 \%$ in patients with osteosarcoma. These results are in line with literature data and with the tumor necrosis rate which is currently the strongest clinical prognostic factor after chemotherapy [2,23,24].

Overall, the molecular complexity of osteosarcoma makes the known prognostic markers of limited utility $[12,25]$. A multiple panel of biomarkers in addition to clinical parameters would be useful for predicting prognosis [25]. In this setting, YY1 is the first osteosarcoma marker whose overexpression has been correlated with low metastasis-free and poor overall survival in a higher frequency of cases (61\% in the present study) than reported in other studies leading us to set a higher cutoff value (YY1 > 50\%) [12]. In addition, low YY1

Table 1 YY1 scoring as continuous variable

\begin{tabular}{|c|c|c|c|c|c|}
\hline Clinical features & $\begin{array}{c}\text { YY1 - } 0 \\
4 \text { patients }\end{array}$ & $\begin{array}{c}\text { YY1 - } 1 \\
9 \text { patients }\end{array}$ & $\begin{array}{c}\text { YY1 - } 2 \\
4 \text { patients }\end{array}$ & $\begin{array}{c}\text { YY1 - } 3 \\
9 \text { patients }\end{array}$ & $\begin{array}{c}\text { YY1 - } 4 \\
15 \text { patients }\end{array}$ \\
\hline Age & $16.3 \pm 7.4$ & $30.1 \pm 23.9$ & $13.0 \pm 2.2$ & $12.3 \pm 8.9$ & $19.7 \pm 13.4$ \\
\hline \multicolumn{6}{|l|}{ Gender } \\
\hline Male & 25.0 & 66.7 & 100.0 & 66.0 & 73.3 \\
\hline Chemonecrosis $\geq 90 \%$ & 50.0 & 33.3 & 25.0 & 33.3 & 40.0 \\
\hline Metachronous metastasis (\%)* & 0 & 12.5 & 75.0 & 60.0 & 88.9 \\
\hline Mortality & 25.0 & 22.2 & 50.0 & 66.7 & 53.3 \\
\hline Mean follow -up & $50.3 \pm 31.6$ & $39.7 \pm 21.0$ & $62.0 \pm 37.3$ & $43.6 \pm 23.0$ & $48.5 \pm 25.6$ \\
\hline
\end{tabular}

*Data reported are from the 27 patients free of metastasis at baseline and expressed in percentage 
Table 2 Univariate analysis of YY1 expression and clinical pathological characteristics of patients

\begin{tabular}{|c|c|c|c|c|}
\hline Clinical features & $\begin{array}{l}\text { Number of } \\
\text { cases } 41\end{array}$ & $\begin{array}{l}\text { YY1(low) (0-50\% positive cells) } 16 \\
\text { cases }(39.0 \%)\end{array}$ & $\begin{array}{c}\text { YY1 (strong) }(51 \%-100 \% \text { positive cells) } 25 \\
\text { cases }(61.0 \%)\end{array}$ & $\mathrm{p}$ \\
\hline Age (4-76) & $19.4 \pm 15.6$ & $24.4 \pm 19.1$ & $16.2 \pm 12.0$ & 0.099 \\
\hline \multicolumn{5}{|l|}{ Gender } \\
\hline Male & 68.3 & 62.5 & 72.0 & 0.524 \\
\hline Chemonecrosis $\geq 90 \%$ & 36.6 & 37.5 & 36.0 & 0.923 \\
\hline Synchronous metastasis (\%) & 34.1 & 25.0 & 40.0 & 0.323 \\
\hline Metachronous metastasis (\%) * & 55.6 & 25.0 & 80.0 & 0.004 \\
\hline $\begin{array}{l}\text { Mean time to metastasis (range } 3 \text { - } \\
76 \text { months) }\end{array}$ & $29.4 \pm 19.2$ & $37.6 \pm 22.9$ & $22.9 \pm 13.1$ & 0.047 \\
\hline Mortality & 46.3 & 18.8 & 64.0 & 0.005 \\
\hline $\begin{array}{l}\text { Mean follow-up (range 3-95 } \\
\text { months) }\end{array}$ & $47.0 \pm 25.3$ & $49.8 \pm 27.5$ & $45.2 \pm 24.2$ & 0.578 \\
\hline
\end{tabular}

* Data reported are from the 27 patients free of metastasis at baseline

Table 3 Multivariate Cox regression analysis on incidence of metachronous metastasis

\begin{tabular}{lccc}
\hline Variable & HR & Metachronous metastasis (95.0\% Cl) & $\mathbf{p}$ \\
\hline Age & 1.005 & $0.969-1.043$ & 0.772 \\
Gender (male) & 1.057 & $0.230-4.850$ & 0.944 \\
Histology & 1.201 & $0.321-4.493$ & 0.786 \\
Chemonecrosis $\geq 90 \%$ & 0.717 & $0.219-2.348$ & 0.582 \\
YY1 in primary site (strong vs low) & 4.690 & $1.079-20.396$ & 0.039 \\
\hline
\end{tabular}

$\mathrm{HR}=$ Hazard Rate

expression was correlated with best clinical prognosis and absence of metastasis during follow-up. One common limitation of immunohistochemical studies is both antibody sensitivity and specificity. To address these

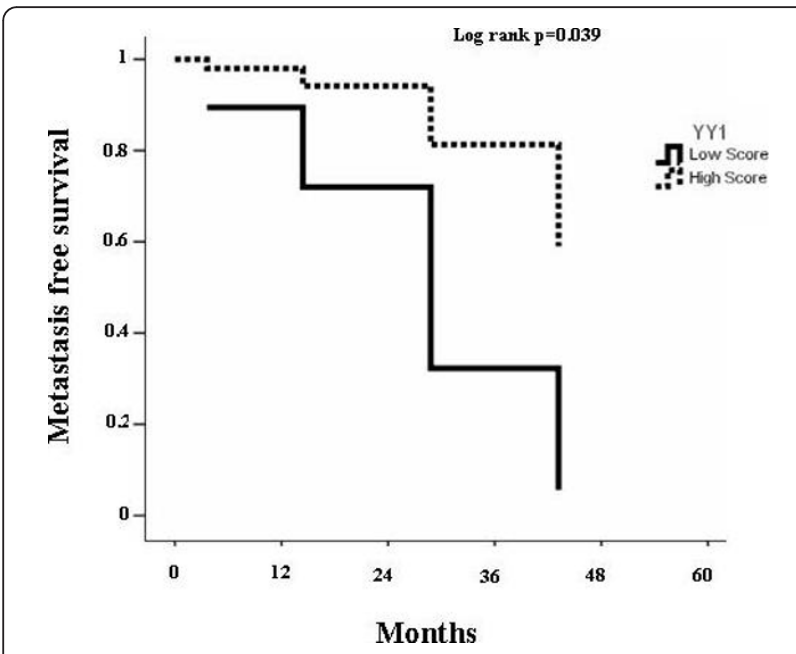

Figure 2 Cox regression of cumulative metastasis-free survival rate. The graph shows the cumulative metastasis-free survival of high grade osteosarcoma patients using Cox multivariate analysis. The data indicates that high score of $Y Y 1$ is associated with higher probability of developing metastasis during the follow up ( $\mathrm{HR}=$ 4.690, $95 \% \mathrm{Cl}=1.079-20.396 ; \mathrm{p}=0.039)$. $\mathrm{HR}=$ hazard ratio; $\mathrm{Cl}=$ confidence interval. issues, we used an antibody previously tested by other groups [26,27]. Immunohistochemistry was also performed in two different Institutions which studied different subgroups of patients [26,27]. YY1 was localized in the nucleus irrespective of histologic subtype, patient age, or tumor site. Although this is a small study, there was no significant difference in YY1 scores between

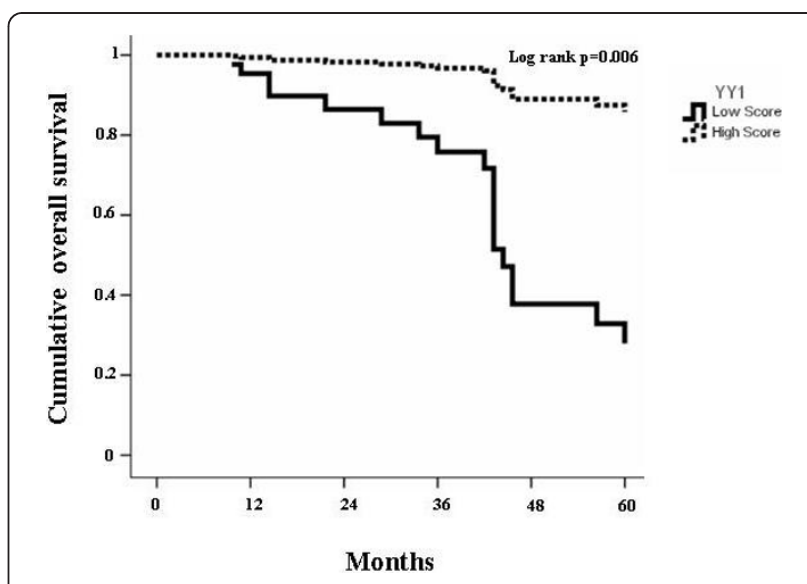

Figure 3 Cox regression of cumulative survival rate of all patients. The graph shows the cumulative overall survival rate of high grade osteosarcoma patients ( $n=41$ ) using Cox multivariate analysis. The data indicates that higher score of YY1 (3-4) predicts mortality during the follow up. $(\mathrm{HR}=8.353,95 \% \mathrm{Cl}=1.863-37.451, \mathrm{p}$ = 0.006) $\mathrm{HR}=$ hazard ratio; $\mathrm{Cl}=$ confidence interval. 
Table 4 Association between YY1 overexpression and probability of survival and median survival

\begin{tabular}{cccc}
\hline Years after the first visit & \% of survival patients $\mathbf{4 1}$ cases & \multicolumn{2}{c}{ of survival patients per year stratified for YY1 } \\
YY1 Low (16 cases) & 94 & 96 \\
\hline 1 & 95 & 94 & 84 \\
2 & 88 & 86 & 72 \\
3 & 77 & 79 & 39 \\
4 & 53 & 79 & 34 \\
5 & 50 & 79 & 34 \\
6 & 50 & 79 & 34 \\
7 & 50 & 84 & 44 \\
\hline
\end{tabular}

younger and older age groups suggesting its role in tumor development. The design of the present study stemmed from our previous in vitro observations demonstrating that YY1 was overexpressed in osteosarcoma cells and tissues with more aggressive phenotype [16-18]. This is in agreement with YY1 overexpression in prostate, gastrointestinal $[26,27]$ and other tumors [14]. Moreover, in an in vivo mice model of osteosarcoma YY1 was also shown to play a key role in metastatic growth [19] by regulating vascular supply [20,28].

Interestingly, the majority of patients analyzed revealed strong YY1 expression and showed poor response to chemotherapy based on Huvos grading system. Although the correlation between YY1 expression and prognosis may merely be a statistical association, the protein dosage points to a functional relationship between YY1 overexpression and a more aggressive tumor phenotype. Noteworthy, literature data from other tumoral and non-tumoral tissues provide at least some evidence for the proposed functional relationship. Resistance to Fas-mediated apoptosis of prostate cancer cells is linked to YY1 [29]. A further potential link between YY1 overexpression and chemoresistance lies in the fact that YY1 regulates DR5 gene [30]. We have recently demonstrated that YY1 is involved in CXCR4 and VEGF pathways $[19,20]$ which have both been genetically amplified and correlated with poor survival of soft-tissue sarcomas $[8,31,32]$. In addition, YY1 overexpression increases resistance to taxana treatment in epithelial ovarian cancer [32]. Furthermore, in a meta-

Table 5 Multivariate Cox regression analysis of clinical variables on overall survival

\begin{tabular}{lccc}
\hline Variable & HR & $\mathbf{( 9 5 \% ~ C l )}$ & $\mathbf{p}$ \\
\hline Age & 1.046 & $1.014-1.079$ & 0.004 \\
Gender (male) & 0.628 & $0.187-2.110$ & 0.452 \\
Metastasis & 1.282 & $0.462-3.558$ & 0.634 \\
Histology & 0.780 & $0.365-1.666$ & 0.521 \\
Chemonecrosis $\geq 90 \%$ & 0.293 & $0.097-0.884$ & 0.029 \\
YY1 in primary site (strong vs low) & 8.353 & $1.863-37.451$ & 0.006 \\
\hline
\end{tabular}

$\mathrm{HR}=$ Hazard Rate analysis, YY1 was scored as the most significant gene upregulated in metastatic breast cancer [33]. Thus, YY1 screening may be useful in optimizing individual therapy management at the time of diagnosis in these patients.

In conclusion, we demonstrated for the first time that high YY1 expression in osteosarcoma is associated with metastasis development and mortality independently of age, gender, histotype and presence of metastasis at baseline. While other studies have analyzed larger cohorts of patients $[34,35]$, this is the first time a prognostic marker has demonstrated poor outcome by multivariate analysis. If data are confirmed in a larger cohort of patients, YY1 may become part of a multiple panel of biomarkers clinically useful for osteosarcoma prognosis.

\section{Conclusions}

Our study established that overexpression of YY1 in primary site of osteosarcoma is associated with the occurrence of metastasization and poor clinical prognosis. This may be a novel marker for patients with osteosarcoma.

\section{Acknowledgements}

We thank Sig. Concetta Aiello for her technical support. This work was supported by grant from the "Fondi di Ateneo 2008" to the Second University of Naples (F.DN. and C.N.) and from the "Progetto di Rilevante Interesse Nazionale Ministero Italiano Università e Ricerca" 2006 [Code 0622153_002 "Meccanismi fisiopatologici di danno vascolare/trombotico ed angiogenesi"] and 2008 [Code T85HLH_002 "Regolazione dell'espressione genica della via SIRT/Foxo1- dipendente in cellule endoteliali progenitrici nella nicchia vascolare] to the Second University of Naples (C.N.)

\section{Author details}

'Department of General Pathology, Division of Clinical Pathology and U.O.C. Immunohematology, Second University of Naples, 80138 Naples, Italy. ${ }^{2}$ Department of Surgical Pathology, Rizzoli Orthopedic Institute, 40136 Bologna, Italy. ${ }^{3}$ Salvatore Maugeri Foundation, Telese-Terme, 82037 Benevento, Italy. ${ }^{4}$ Division of Pathology National Cancer Institute, Pascale Foundation, 80131 Naples, Italy. ${ }^{5}$ Division of Thoracic Surgery, Sarcoma Team National Cancer Institute, Pascale Foundation, 80131 Naples, Italy. ${ }^{6}$ SDN Foundation, Institute of Diagnostic and Nuclear Development, via E. Gianturco 113, 80143 Naples, Italy. ${ }^{7}$ Department of Human Pathology, Federico II University of Naples, 80131 Naples, Italy. ${ }^{8}$ Department of Human Pathology, Second University of Medicine, 80138 Naples, Italy. 


\section{Authors' contributions}

LZ, RR and GC performed immunohistochemistry experiments. FC performed statistical analysis and had responsibility for integrity of database. AM and DC grading evaluations of osteosarcoma patients. FDN and CN designed the study and wrote the manuscript. All the authors read and approved the final version of the manuscript.

\section{Competing interests}

All authors have no potential conflict of interest including any financial, personal or other relationships with other people or organizations within that could inappropriately influence (bias) their work.

Received: 26 May 2011 Accepted: 2 November 2011

Published: 2 November 2011

\section{References}

1. Bacci G, Longhi A, Versari M, Mercuri M, Briccoli A, Picci P: Prognostic factors for osteosarcoma of the extremity treated with neoadjuvant chemotherapy 15-year experience in 789 patients treated at a single institution. Cancer 2006, 106:1154-1161.

2. Bielack SS, Kempf-Bielack B, Delling G, Exner GU, Flege S, Helmke K, Kotz R, Salzer-Kuntschik M, Werner M, Winkelmann W, Zoubek A, Jürgens H, Winkler K: Prognostic factors in high-grade osteosarcoma of the extremities or trunk: an analysis of 1,702 patients treated on neoadjuvant cooperative osteosarcoma study group protocols. J Clin Oncol 2002, 20:776-790.

3. Picci P, Mercuri M, Ferrari S, Alberghini M, Briccoli A, Ferrari C, Pignotti E, Bacci G: Survival in high-grade osteosarcoma: improvement over 21 years at a single institution. Ann Oncol 2010, 21:1366-1373.

4. Longhi A, Errani C, De Paolis M, Mercuri M, Bacci G: Primary bone osteosarcoma in the pediatric age: state of the art. Cancer Treat Rev 2006, 32:423-436.

5. Kim MS, Lee SY, Lee TR, Cho WH, Song Ws, Koh JS, Lee JA, Yoo JY, Jeon DG: Prognostic nomogram for predicting the 5-year probability of developing metastasis after neo-adjuvant chemotherapy and definitive surgery for AJCC stage II extremity osteosarcoma. Ann Oncol 2009, 20:955-960.

6. Bacci G, Longhi A, Ferrari S, Lari S, Manfrini M, Donati D, Forni C, Versari M: Prognostic significance of serum alkaline phosphatase in osteosarcoma of the extremity treated with neoadjuvant chemotherapy: recent experience at Rizzoli Institute. Oncol Rep 2002, 1:171-175.

7. Serra M, Scotlandi K, Reverter-Branchat G, Ferrari S, Manara MC, Benini S, Incaprera M, Bertoni F, Mercuri M, Briccoli A, Bacci G, Picci P: Value of Pglycoprotein and clinicopathologic factors as the basis for new treatment strategies in high-grade osteosarcoma of the extremities. J Clin Oncol 2003, 3:536-542.

8. Laverdiere C, Hoang BH, Yang R, Sowers R, Qin J, Meyers PA, Huvos AG, Healey JH, Gorlick R: Messenger RNA expression levels of CXCR4 correlate with metastatic behavior and outcome in patients with osteosarcoma. Clin Cancer Res 2005, 11:2561-2567.

9. Osaka E, Suzuki T, Osaka S, Yoshida Y, Sugita H, Asami S, Tabata K Hemmi A, Sugitani M, Nemoto N, Ryu J: Survivin as a prognostic factor for osteosarcoma patients. Acta Histochem Cytochem 2006, 3:95-100.

10. Kim C, Shin E, Hong S: Clinical value of ezrin expression in primary osteosarcoma. Cancer Res Treat 2009, 41:138-144.

11. Sadikovic B, Thorner P, Chilton-Macneill S, Martin JW, Cervigne NK, Squire J, Zielenska M: Expression analysis of genes associated with human osteosarcoma tumors shows correlation of RUNX2 overexpression with poor response to chemotherapy. BMC Cancer 2010, 10:202-211.

12. Clark JC, Dass CR, Choong PF: A review of clinical and molecular prognostic factors in osteosarcoma. J Cancer Res Clin Oncol 2008, 134:281-297.

13. Gordon S, Akopyan G, Garban H, Bonavida B: Transcription factor YY1: structure, function, and therapeutic implications in cancer biology. Oncogene 2006, 25:1125-1142.

14. Zaravinos A, Spandidos DA: Yin Yang expression in human tumors. Cell Cycle 2010, 9:512-522.

15. Rizkallah R, Alexander KE, Kassardjian A, Lüscher B, Hurt MM: The transcription factor YY1 is a substrate for Polo-like kinase 1 at the G2/M transition of the cell cycle. PLOS One 2011, 6:e15928.
16. de Nigris F, Botti C, de Chiara A, Rossiello R, Apice G, Fazioli F, Fiorito C, Sica V, Napoli C: Expression of transcription factor Yin Yang 1 in human osteosarcomas. Eur J Cancer 2006, 42:2420-2424.

17. de Nigris F, Botti C, Rossiello R, Crimi E, Sica V, Napoli C: Cooperation between Myc and YY1 provides novel silencing transcriptional targets of alpha3beta1-integrin in tumour cells. Oncogene 2007, 26:382-394.

18. de Nigris F, Rossiello R, Schiano C, Arra C, Williams-lgnarro S, Barbieri A, Lanza A, Balestrieri A, Giuliano MT, Ignarro LJ, Napoli C: Deletion of Yin Yang 1 protein in osteosarcoma cells on cell invasion and CXCR4/ angiogenesis and metastasis. Cancer Res 2008, 68:1797-1808.

19. de Nigris F, Crudele V, Giovane A, Casamassimi A, Giordano A, Garban HJ, Cacciatore F, Pentimalli F, Marquez-Garban DC, Petrillo A, Cito L, Sommese L, Fiore A, Petrillo M, Siani A, Barbieri A, Arra C, Rengo F, Hayashi T, Al-Omran M, Ignarro L, Napoli C: CXCR4/YY1 inhibition impairs VEGF network and angiogenesis during malignancy. Proc Natl Acad Sci USA 2010, 107:14484-14489.

20. Napoli C, Giordano A, Casamassimi A, Pentimalli F, Ignarro L, de Nigris F: Directed in vivo angiogenesis assay and the study of systemic neoangiogenesis in cancer. Int I Cancer 2011, 120:1505-1508.

21. Marcove RC, Heelan RT, Huvos AG, Healey J, Lindeque BG: Osteoid osteoma. Diagnosis, localization, and treatment. Clin Orthop Relat Res 1991, 267:197-201.

22. Baldini N, Scotlandi K, Barbanti-Bròdano G, Manara MC, Maurici D, Bacci G, Bertoni F, Picci P, Sottili S, Campanacci M: Expression of P-glycoprotein in high-grade osteosarcomas in relation to clinical outcome. N Engl J Med 1995, 333:1380-1385.

23. Rasalkar DD, Chu WC, Lee V, Paunipagar BK, Cheng FW, Li CK: Pulmonary metastases in children with osteosarcoma: characteristics and impact on patient survival. Pediatr Radiol 2011, 41:227-236.

24. Davicioni E, Wai DH, Anderson MJ: Diagnostic and prognostic sarcoma signatures. Mol Diagn Ther 2008, 12:359-374.

25. Tainsky MA: Genomic and proteomic biomarkers for cancer: a multitude of opportunities. Biochim Biophys Acta 2009, 1796:176-193.

26. Seligson D, Horvath S, Huerta-Yepez S, Hanna S, Garban H, Roberts A, Shi T, Liu X, Chia D, Goodglick L, Bonavida B: Expression of transcription factor Yin Yang 1 in prostate cancer. Int J Oncol 2005, 27:131-141.

27. Chinnapan D, Xiao Dm, Ratnasari A, Andry C, King TC, Weber HC: Transcription factor YY1 expression in human gastrointestinal cancer cells. Int J Oncol 2009, 34:1417-1423.

28. Huerta-Yepez S, Vega M, Garban H, Bonavida B: Involvement of the TNFalpha autocrine-paracrine loop, via NF-kappaB and YY1, in the regulation of tumor cell resistance to Fas-induced apoptosis. Clin Immunol 2006, 120:297-309.

29. Baritaki S, Suzuki E, Umezawa K, Spandidos DA, Berenson J, Daniels TR, Penichet ML, Jazirehi AR, Palladino M, Bonavida B: Inhibition of Yin Yang 1dependent repressor activity of DR5 transcription and expression by the novel proteasome inhibitor NPI-0052 contributes to its TRAIL-enhanced apoptosis in cancer cells. J Immunol 2008, 180:6199-6210.

30. Oda $\mathrm{Y}$, Tateishi $\mathrm{N}$, matono $\mathrm{H}$, matsuura $\mathrm{S}$, Yamamaoto $\mathrm{H}$, Tamiya $\mathrm{S}$, Yokiyama R, matsuda S, Iwamoto $Y$, Tsuneyoshi M: Chemokine receptor CXCR4 expression is correlated to VEGF expression and poor survival in soft tissue sarcoma. Int J Cancer 2009, 124:1852-1859.

31. Yang J, Yang D, Sun Y, Sun B, Wang G, Trent J, Araujo D, Chen K, Zhang W, Matsumura N: Genetic amplification of the vascular endothelial growth factor (VEGF) pathway genes, including VEGFA, in human osteosarcoma. Cancer 2011

32. Huang Z, Baba T, Lee PS, Barnett JC, Mori S, Chang JT, Kuo WL, Gusberg AH, Whitaker RS, Gray JW, Fujii S, Berchuck A, Murphy SK: Yin Yang 1 modulates taxane response in epithelial ovarian cancer. Mol Cancer Res 2009, 7:210-220.

33. Thomassen $M$, Tan $Q$, Kruse TA: Gene expression meta-analysis identifies metastatic pathways and transcription factors in breast cancer. BMC Cancer 2008, 8:394.

34. Urakawa H, Nishida Y, Naruse T, Nakashima H, Ishiguro N: Cyclooxygenase2 overexpression predicts poor survival in patients with high-grade extremity osteosarcoma a pilot study. Clin Orthop Relat Res 2009, 467:2932-2938.

35. Urakawa H, Nishida $Y$, Nakashima H, Shimoyama Y, Nakamura S, Ishiguro N: Prognostic value of indoleamine 2,3-dioxygenase expression in high grade osteosarcoma. Clin Exp Metastasis 2009, 26:1005-1012. 


\section{Pre-publication history}

The pre-publication history for this paper can be accessed here: http://www.biomedcentral.com/1471-2407/11/472/prepub

doi:10.1186/1471-2407-11-472

Cite this article as: Nigris et al:: YY1 overexpression is associated with poor prognosis and metastasis-free survival in patients suffering osteosarcoma. BMC Cancer 2011 11:472.

Submit your next manuscript to BioMed Central and take full advantage of:

- Convenient online submission

- Thorough peer review

- No space constraints or color figure charges

- Immediate publication on acceptance

- Inclusion in PubMed, CAS, Scopus and Google Scholar

- Research which is freely available for redistribution

Submit your manuscript at 